\title{
PORTFOLIO DECISIONS ON THE INSURANCE MARKET
}

\author{
Adrian Victor BADESCU, adi_bad@yahoo.com \\ Professor PhD, Academy of Economic Studies of Bucharest \\ Adriana Elena SIMION (ISTRATE), adriana.istrate@asiban.ro \\ PhD Candidate, Academy of Economic Studies of Bucharest
}

\begin{abstract}
A combination of titles can define the term portfolio.
To decide means to take a favorable position for a certain point of view regarding a subject or a problem and to chose the best at that particular juncture from many possible ways, to achieve a certain mean or to resolve a problem.

The insurance domain has a very important status in the globalization context and social transformation.

Lately, few Romanian insurance companies have been overtaken by international companies. The appeal of national companies is determinate by the real assets and financial assets owned by those companies and, of course, the market potential.
\end{abstract}

\section{General terms}

A more complex definition of the portfolio could be: the owning by an individual or by a legal person of some values from more than one issuer.

The portfolios can be classified as active portfolios and inactive portfolios:

An active portfolio denotes owning of more values having as an objective the improvement of the investment performance

An inactive portfolio denotes owning of titles from more issuers.

For an investor, the advantage of making a portfolio can be given by the reduction of risks trough the diversity of titles. The risk is closely attached to the profitability.

The profitability of a portfolio is represented by the average of the individual profitability of the titles from the portfolio.

By its definition, the risk illustrates the doubtfulness caused by the happening of future events, while the uncertainty is given by the probability law.

In the portfolio theory it's easy to observe the risk of an individual title is of different importance compared to the situation in which this is part of a portfolio.

A title can be very risky for an investor who puts all his money in this title and it can represent a lower risk in the case of investing just a part of his money, the rest being used for other titles. An adverse evolution of all the titles is unlikely, which leads to a very low risk.

\section{Markowitz model}

The relationship between risk and profitability was firstly described by Markowitz.

He showed that in conditions of certitude the option for a portfolio can be made through dispersion analyses and the profit ratio expected for that portfolio.

Since 1952, Markowitz warned the investors about the fact that they should be interested in the volatility and the risk of the investments they made, not only about their profitability, in order to reach an optimum investment. 
In 1990, Harry Markowitz was awarded the Nobel Prize for economy with the article 'Portfolio Selection'.

His theory concerning the portfolios selection represented an important step forward because before that, the portfolios management patterns were based on the incomes generated by the investment opportunities and considered their profitability as being significant.

Markowitz is the one who introduced the notion of risk. In his theory, Markowitz gives the risk the same importance as to the notion of profitability, and proposes the dispersion as a measure of this.

The risk of the diversified portfolio depends on the adverse movements of all the titles and of the individual dispersion of their profitableness.

Markowitz proved that an investor can reduce the volatility of his portfolio and can dictate its increase of profitableness at the same time.

Starting from the profitableness and the risk of a diversified title portfolio, Markowitz founded a pattern applicable in the portfolio theory domain.

The hypothesis underlying this pattern refers both to the investor's behaviour and to the titles behaviour.

The hypothesis concerned with the investor's behaviour is:

$>$ The investors have aversion to risk and pursue the maximization of the utility.

$>$ The risk is described by the profitableness dispersion and its known and accepted by the investors.

$>$ There is a probability law, which refers to the repartition of the profitableness, possible to achieve on the title holding period.

$>$ The investors use profitableness and dispersion to make decisions.

Referring to the title behaviour, it is considered that the titles, of which the portfolio is made of, are risky titles, characterized by a certain hope of profitableness, dispersion and covariant with the other selected titles.

For the portfolio selection there are two stages:

In the first stage the value titles existing on the market are analysed in order to establish the optimum proportion of titles inside the portfolio.

In the second stage, based on the analysis from the first stage, the future performances of the value titles are predicted and there is established a titles portfolio that can offer the maximum profitability. In this phase scenarios are being elaborated regarding the risk evolution and the future profitability, based on the previous predictions.

Markowitz model allows the investor to decide the options that satisfy the criterion profitableness - risk, always pursuing the maximization of the profitableness and the minimization of the risk.

The application of this pattern allows the achievement of that title combination that can offer the lowest risk level, by the determination of the portfolio with the absolute minimal variant, and also it allows the determination of the efficiency border on which the optimum portfolio is situated.

The efficiency border begins by the determination of the portfolio with the absolute minimal variant predicted by the investors with the biggest risk aversion.

The elimination from the efficiency border of the specific component of the individual risks of the titles in the portfolio leads to the reduction of the portfolio risk.

Using the Markowitz average-dispersion theory, the investors can get to the optimum portfolios. The optimum portfolio analysis represents the essence of the portfolio decisions.

A definition of the optimum portfolio could be that it represents the lowest risk portfolio for a certain profitableness ratio, in other words it is pursued the highest performance of an 
indicator, watched by the investor, keeping the level of the others indicators. Moreover, in the case of optimum portfolios the spreading is minimal.

By the formation of the optimum portfolio is intended:

- Reaching the given profitability at a minimum risk, case in which is preferred certain profitability and a minimum risk is pursued.

- Reaching the given risk and a maximum profitableness, case in which exceeding a certain risk level is not desired but the reach of the maximum profitability.

Concluding, we can say that the optimum portfolio satisfies the utility function of the investors that present aversion to risk.

The majority of the patterns in the portfolio theory, although they are perfect from the logical and construction point of view, when they are applied they simply don't lead to the estimated results.

Inside these models a perfect market is analyzed. On this market there is no dominant investor and also there is no investor that can affect the titles course, taxes or contributions are not taken into consideration or the costs concerning the transactions. The titles can be divided continuously, and any investor has free access to the information. A perfect market can also be efficient.

The information about a title is lying in its course. The analyze of this course is what it renders the best the value expression of that title.

The information about a title can be both of favourable and unfavourable nature. The favourable information make the potential investors buy, leading to the course rising. As for the unfavourable information, the potential investors don't buy and the course falls. Thus, the title course fluctuates in a random way, and the new information appears by chance.

In order to determine whether a market is efficient or not it is necessary to test which type of information among all the available information is reflected in the title price.

In conclusion, it can be said that it is difficult to constitute optimum portfolios, especially if we consider the existence of the uncertainty in the case of the title price evolution on a long term.

The investors are setting themselves various objectives to be reached. These objectives differ in accordance with the investors' interests regarding the profit and the risk brought by the investment. It can be taken into consideration a big profit with a high risk or with a low risk but with a smaller profitability.

The investment in a sole title can lead to high profits, but the risk is also very high in the case this title value falls. In this situation the investor is taking a maximal risk on a long term. After a statistical analysis it is gotten to the conclusion that the titles speculation can bring great benefits on short terms, after which the invested capital must be reoriented to the acquisition of other titles.

It is very important to analyze the contribution of a title to the risk and to the profitableness of the portfolio in which is included. This analysis started from the diversification. In certain situations it is possible to make portfolios that have a lower risk than the one of each title of which is made of.

Also the diversification leads to the existence of a minimum risk portfolio. This portfolio has the minimum positive risk, excepting the case in which the correlation coefficient reaches the minus one value and the risk in null.

A title is chosen to be included in a portfolio according to its behaviour inside the portfolio, and not according to its individual characteristics. Even if a title is very risky but is correlated weakly with the titles from the portfolio, can bring a mild contribution to the portfolio 
risk. But if the correlation is negative, the title is attractive due to its diminishing effect it brings to the portfolio risk in which is included.

The risk of a title depends of the portfolio in which is included. The investors are observing the investment of the money they own in the portfolios with low risk titles.

An efficient portfolio is desired. This portfolio is the one that has the lowest risk for an expected turnover.

The investor's strategy is the one where the multitude of his desires meets the multitude of his possibilities.

The multitude of possibilities is given by the efficiency frontier which is obtained from the multitude of the investor's anticipations concerning the individual titles, while the multitude of wishes in built on the indifference curves that reflect the investor's preferences from his utility function and are obtained from the utility function.

The investor will only consider the efficient portfolios; he will only choose the one that corresponds to the tangent point of the two curves. This point illustrates the optimum portfolio.

The investor will choose the portfolio in accordance with his aversion for risk. If his aversion is strong, the investor chooses the portfolio that is situated on the left side of the efficiency frontier corresponding with the lowest risk level, otherwise he will choose the portfolio situated on the right side of the frontier.

\section{Investment on the insurance market from Romania}

The decisions that are the consequences of investment and profitableness analysis in insurance:

The investors (present and potential) are interested to find the benefit of the investments and its risk. Taking in consideration the rate of profitableness or per share profit, they decide if they want shares or nor at that insurance company. They can also decide to sell or buy more shares.

The customers are the most important group and they are interested by the capability of the company to have continuity, also the credibility on the market is very important. This information determinate eider making or braking of an agreement between them.

Insurance brokers are interested if the amounts owed are paid within the period stated in the agreement. This information affects the option to continue the collaboration or breaking it.

The employees are interested of the stability of the company, but also of the capacity to be paid for their work and other advantages. They decide their degree of involvement in the company based on those facts.

Creditors are also a very important group. They can affect course of activity and are interested by the payment capacity of loans and interests.

Financial Management has made quantum leaps in the last decades.

There are tough big companies who don't use the most advanced financial techniques. They do that not because those techniques are very complex, but because the rhythm of changes is very fast.

Lately, some insurance companies have been acquired by international groups.

"Asitrans insurance" is a middle market player in the top of insurance companies in Romania. This company has recorded, in the first semester of this year, subscribed premiums of 14.5 million euro. Compared with the last year premiums of the same period, a $45 \%$ increase is seen. This company has been recently acquired by the Bulgarian group Eurohold. The acquisition has been approved by the Insurance Supervisory Commission. The Bulgarian group invested 12.5 million euro for $75 \%$ of the shares and also the majority shares from Asitrans Leasing. 
Asirom is a well known brand on the Romanian market. According to the classification made by the Insurance Supervisory Commission, Asirom occupies the second place. The majority of shares have been acquired by Vienna Insurance Group, this group has a share of 17.73 of the local insurance market.

The total value of Asirom is 169 millions euro. This company obtained a brut profit in 2006 of 14 millions Lei, after the net losses of 36 million Lei from 2005.

In Romania, Vienna Insurance Group controls directly the following companies: Omniasig with 97.78 of shares, and Unita, with 99,99\% of the shares, and have a big influence of Omniasig Life insurance and Agras. Vienna Insurance Group has 50\% of the shares of Omniasig Life Insurance and $75.7 \%$ of Agras.

Asirom Insurance estimates a threefold increase in subscribed premiums in 2009 to a value of 570 million euro, compared with the level achieved at the end of 2006.

Asiban is the $4^{\text {th }}$ insurance company according to the Insurance Supervisory Commission on general insurance market. Rothschild, the European investments bank, who was the consultant in the acquisition process of Romanian Bank of Commerce, has been commission to handle the sale of Asiban, besting the American bank, Merrill Lynch. The action that did determinate this was held by the three major share holders of Asiban: Romanian Bank of Commerce, BRDGroupe Société Générale, and Transilvania Bank who decided to sell $75 \%$ of the shares that they own.

The acquisition of Asiban may be the biggest transaction of this year in the financial sector. In the last years, in the major transaction of this sector the mean price was 0,8 euro per euro from the turnover (subscribed premiums). This will take the entire value of Asiban to a value of 100 million euro. After choosing the consultant, an internal audit will be made, and also an evaluation. For the first 5 month of this year, Asiban had a profit of around 1 million euro.

Astra Insurance is situated on the 7th place on the same top. This company was acquired by the biggest insurance company in Austria, Uniqa. The Austrians have increased the participation in Astra-Uniqa from $27 \%$ to $50 \%$ plus 1 share by acquiring a package of shares from Nova Trade, the company own by the business man Dan Adamescu. The whole transaction was valued at 10 million euro.

In the insurance market, the main competitor of Uniqa group is Vienna Insurance Group (VIG), which entered the Romanian market in 2001 by acquiring $51 \%$ of the insurance company Unita.

The interest shown by those international companies is due to the great potential of the Romanian insurance market. This potential is determinate by the fact that the vast majority of contracts on the market are in the automotive incurrence sector and by new regulations and the growth of the economy in general.

These legal regulations are increasing the potential of the market and the diversity of the portfolio.

\section{Bibliography:}

1. Badescu A.V., Dobre I., Modelarea deciziilor finaciare,Editura Conphys, Rm. Vilcea, 2001

2. Ben-Haim, Yakov, Decisions Under Severe Uncertainty, Info-Gap, 2006

3. Joyce, J.M. , The Foundations of Causal Decision Theory, Cambridge University Press, 2004 
4. Weirich, P. , Realistic Decision Theory: Rules for Nonideal Agents in Nonideal Circumstances, Oxford University Press, 2004.

5. White. D.J. - Decision Theory, Aldine Transaction, 2006, USA. 